\title{
AS FONTES DE DUARTE PACHECO PEREIRA NO "ESMERALDO DE SITU ORBIS" (VII).
}

\section{(Conclusão) .}

Como dissemo - logo no início dêste estudo - apesar do Esmeraldo de situ orbis de Duarte Pacheco Pereira ter sido até agora quase unânimemente considerado como um roteiro da costa de Africa, a verdade é que se trata de uma obra que encerra aspectos que nos levam a considerá-la como um texto bastante complexo. Poderemos mesmo dizer que se trata de uma obra-síntese. Síntese de todo um conjunto de obras anteriores, estreitamente ligadas aos descobrimentos maritimos portuguêses do século XV, e inícios do século XVI. Parece-nos indiscutível que na obra de Duarte Pacheco podemos surpreender um livro de história, com traços bem nítidos de crônica medieval, sobretudo se nos lembrarmos da única crônica do século XV que se ocupa de viagens de descobrimento, a Crônica dos feitos de Guiné de Gomes Eanes de Zurara. Não nos parece menos indiscutível que a obra de Duarte Pacheco nos surge também como um livro de cosmografia e um regimento de navegação. Por outro lado, as vistas de costa e dois autênticos mapas levaram alguns historiadores a considerá-la como um atlas. Finalmente, somos levados a afirmar que a obra de Duarte Pacheco Pereira é, no entanto, antes de mais nada, um roteiro, ao mesmo tempo que um livro de geografia e de cosmografia. Duarte Pacheco Pereira classifica-a, êle próprio, como um livro de cosmografia e marinharia.

A obra de Pacheco, redigida entre 1505 e 1508, logo após a realização daquilo a que chamamos os grandes descobrimentos marítimos, herdeira de uma tradição de quase um século de viagens, herdeira de uma tradição de mais de meio século de Crônicas ocupando-se da Expansão, herdeira de uma tradição de mais de meio século de Descrições de terras longínquas, de Diários de bordo, de Roteiros, de Regimentos de navegação (205), a obra de Pacheco - dizíamos -, surge-nos como uma obra-síntese nó começo de um século, o XVI, que herdava do anterior o conhecimento do globo terrestre. Não foi certamente por acaso que Duarte Pacheco Pereira lhe atribuiu o título que durante tantos anos constituiu um enigma indecifrável. 
O Esmeraldo de situ orbis não é, afinal, nem mais nem menos do que o De Situ Orbis de Pacheco, o De Situ Orbis dos tempos modernos, destinado a substituir o De Situ Orbis da Antigüidade, o De Situ Orbis de Pompônio Mela (206).

Mas se o Esmeraldo de situ orbis é uma obra-sintese, também o seu autor, Duarte Pacheco Pereira, é uma personagem-síntese. Se Duarte Pacheco foi o cavaleiro de D. João II (207); se foi o chefe militar prestigioso, célebre pelas suas façanhas na fndia, entre 1503 e 15,05; se foi o chefe militar da vitoriosa batalha naval de 1509 contra o corsário francês Mondragon, por alturas do Cabo Finisterra (208); se foi, em 1511, o comandante da frota enviada em socôrro de Tânger, quando esta cidade estava a ser atacada pelos exércitos do rei de Fez (209); se foi ainda, entre 1519 e 1522, o capitão e governador de São Jorge da Mina (210), a verdade é que também foi o navegador e técnico de navegação, encarregado de reconhecer muitos pontos da costa de Africa, de dirigir em 1498 uma expedição secreta

(205). - Ver, sôbre a Literatura Portuguêsa de Viagens da Epoca dos Descobrimentos, as nossos trabalhos: L'historiographie portugaise contemporaine et la littérature de voyages à l'époque des grandes découvertes, in Ibérida - Revista de Filologia -, n.o 4, Rio de Janeiro, dezembro de 1960; O "Esmeraldo de situ orbis" de Duarte Pacheco Pereira na História da Cultura, in Revista de História, n. ${ }^{\circ}$ 60, São Paulo, outubro-dezembro de 1964; O descobrimento do Brasil através dos textos (Ediçóes críticas e comentadas). I. - A "Carta" de Pero Vaz de Caminha. 1. A Literatura Portuguêsa de Viagens da Epoca dos Descobrimentos, in Revista de História, n.o 65, São Paulo, janeiro-małço de 1966; Viagens (Literatura de), in Dicionário de História de Portugal dirigido por Joel Serrão, Iniciativas Editoriais, Lisboa, no prelo.

(206). - Ver, os nossos artigos: A decifração de um enigma: o título "Esmeraldo de situ orbis", in Diário de Lisboa, 23 de malo de 1963. Artigo reproduzido no Boletim Internacional de Bibliografia Luso-Brasileira, Fundação Calouste Gulbenkian Volume IV, n.o 4, outubro-dezembro de 1963. Ver, sobretudo, com o mesmo título, o artigo da Revista de Historia, São Paulo, n.0 58, abril-junho de 1964.

(207). - Ver as primeiras linhas do Prólogo do Livro I do Esmeraldo. Ver ainda, João de Barros: Ásia, Década I, Livro 3, Capítulo 4 (p. 88 da ed. de Antônio Baião, Coimbra, 1932).

(208). - Damião de Gois: Crônica de D. Manuel (Biblioteca de Clássicos Portugúêses), Lisboa, 1910 2a. Parte, Capítulo XLII.

(209). - Arquivo Nacional da Tôrre do Tombo, Chancelaria de D. Manuel, L. 11, fI. 30v.

(210). - Arquivo Nacional da Tôrre do Tombo, Corpo Cronológico, 2a. Parte, maço 85, n.o 200; Ibldem. maço 86 , n.० 30 ; Ibidem, maço 86 , n.० 80; Ibidem maco 86, n.o 88; Ibldem, 1a. Parte, maço 25, doc. 123; Ibldem, 2a. Parte, maço 91, doc. 28; Ibidem, maço 91, doc. 27; Ibidem, Chancelaria de D. João III, L. 51, fl. 184v. - Ver, para êste, e para os pontos anteriores da blografia de Duarte Pacheco Pereira, a nossa obra, em preparação: L"Esmeraldo de situ orbis" de Duarte Pacheco Pereira et Ia littérature portugaise de voyages à l'époque des grandes découvertes. - Só damos a fonte, em nota, nêste final de nosso trabalho. daqueles pontos da biografia de Duarte Pacheco Pereira de que não nos ocupámos nas primeiras páginas dêste mesmo trabalho. 
para ás costas do Brasil (211), de discutir com os castelhanos - como membro da delegação portuguêsa - àcêrca do estabelecimento da famosa linha dita de Tordesillas, e ainda o homem de ciência que, com a antecipação de mais de dois séculos, dá o valor do grau de meridiano com um êrro de apenas $4 \%$, quado o êrro corrente na época variava entre 7 e $15 \%$.

No Esmeraldo podemos surpreender, como já dissémos, um livro de história, com traços bem nítidos de crônica medieval, um livro de cosmografia e um regimento de navegação, um livro de geografia, e finalmente, aquilo que êle é fundamentalmente, um roteiro da costa de África.

A oscilação entre o cronista e o cientista, entre a crônica e o livro científico, é bem visível logo no Prólogo do Livro I, em que Duarte Pacheco, ao definir a sua obra, se define, implicitamente, também a si próprio:

"... e porque Vossa Alteza me disse que se queria nisto fiar de mim, portanto preparei fazer um livro de cosmografia e marinharia, cujo prólogo é este que aqui é escrito, o qual livro será partido em cinco livros, e no primeiro se dirá do que descobrio o virtuoso Infante Dom Anrique, e no segundo do que mandou descobrir o excelente rei Dom Afonso, e no terceiro do que isso mesmo fez descobrir o sereníssimo rei Dom João, que faz fim no ilhéo da Cruz, como já disse; o quarto e o quinto, em que pendem vossos gloriosos feitos, que são mais em cantidade e maiores em calidade que os de tôdolos outros príncipes. O primeiro destes livros começará do dito ilhéo da Cruz em diante, e fará fim no cabo de Guardafune que está na entrada do sino Arábico, e o segundo irá da entrada do sino Arábico até o sino Pérsico, e dali em diante per toda a India; e assi são os ditos cinco livros, e neles se tratará segundo aqui irá prometido; e não tão sòmente serão neceśsários pera proveito desta navegação e comércio, mas ainda para ficar ũa eterna memória e lembrança a nossos sucessores e vindouros, por onde possam saber vossas excilentes façanhas dignas de gloriosa imortalidade. Mas qual eloquềncia terá tanta prefeição, que perfeitamente possa dizer o peso de tão grandes feitos como os do nosso César Manuel? Ca Marco Túlio, o mais excilente dos latinos, e Homero e Demóstenes, os principais oradores dos gregos, que per excilência sua eloquência antre tôdolos mortais até 'gora floreceo. certamente suas mãos temeriam escrever feitos de tamanha gravidade. Mas leixo tudo isto

(211). - Ver, a nossa obra, em preparacão, citada na nota anterior. Ver ainda: o Descobrimento do Brasil através dos textos (Ediçöes críticas e comentadas), em publicação na Revista de História, São Paulo, a partír do n. 65 , janeiro-março de 1966. 
pera quem vossa governança houver de fazer; o que toca a cosmografia e marinharia por extenso espero dizer; e portanto farei primeiro com brevidade menção dalguns círculos superiores, e da cantidade da terra e d'água qual destas duas é a maior parte, decrarando sumáriamente a grandeza d'África e assi d'Ásia, onde vossas vitórias, assi no ouriente como no oucidente, florecem; e destas duas somente e brevemente quanto ao interior da terra se dirá, e o do lito ou costa do mar, tudo o que toca a marinha e cosmografia, mais largamente farei menção; e portanto serão aqui decraradas tôdalas rotas, s. como jaz um promontório ou lugar com outro, e isto porque esta obra leve ordem e fundamento, e a costa mais seguramente se possa navegar, e o mesmo as conhecenças das terras e assi onde estão as baixas, que para isto é muito necessário saber-se; também das sondas que há em alguns lugares, em quanta altura são, e assi as deferenças dos fundos, s. se é vasa ou areia, ou pedra ou saibro, ou arestas ou burgao, ou de que calidade a tal sonda é, e sendo conhecida, quantas léguas haverá dali a terra, e o mesmo as marés se são de nordeste e sudoeste, assi como as da nossa Espanha, ou se são de norte e sul, ou de leste e oeste, ou de noroeste e sueste, as quais para entrarem e sairem nas barras e bocas dos rios são forçadamente necessárias; e assim as alturas de cada um dos polos, por onde se pode saber quantos graos se cada lugar aparta em ladeza da equinocial, e também a natureza da gente desta Etiópia e o seu modo de viver, é assim direi do comércio que nesta terra pode haver; tudo isto com diligência, por serviço de Vossa Alteza, farei, e no melhor modo que poder e souber neste livro será escrito, o qual Esmeraldo de situ orbis será chamado;...".

Duarte Pacheco Pereira escreveu um livro, de cosmografia e marinharia, dividido em cinco partes: a primeira, dedicada ao relato dos descobrimentos do tempo do Infante D. Henrique; a segunda, aos do tempo de $\mathrm{D}$. Afonso V; a terceira, aos do tempo de D. João II; a quarta, e a quinta, dedicada aos descobrimentos do reinado de D. Manuel.

O livro de cosmografia e marinharia dir-se-ia ter-se transformado em livro de história, em crônica, quando o seu autor passa a enunciar o seu conteúdo. E mais. Ainda em relação ao livro de história, à crônica, façamos notar que Duarte Pacheco justifica a sua obra pela eterna memória e lembrança que deve ficar registrada para os nossos sucessores e vindouros, e para que êstes possam saber vossas excilentes façanhas dignas de gloriosa imortalidade. Estamos, neste passo, em pleno panegírico do rei $\mathrm{D}$. Manuel, o monarca todo poderoso no momen- 
to em que Pacheco redigia a sua obra. A Crônica medieval está bem patente nestas linhas do Esmerallo...... Mas Duarte Pacheco Pereira é uma personagem complexa. A sua obra, uma obra complexa. Pacheco é uma personagem-síntese. A sua obra, uma obra-síntese. É que também, no longo passo citado do Prólogo do Livro I, encontramos o Duarte Pacheco Pereira navegador; técnico de navegação, o Duarte Pacheco $\mathrm{Pe}$ reira homem de ciência, homem de acção, o militante, o intelectual da nova classe ascendente, a burguesia comercial... Notemos que, antes de nos falar da eterna memória e lembrança a nossos sucessores e vindouros, Pacheco fala-nos da utilidade da sua obra para a navegação e para o comércio: pera proveito desta navegação e comércio. Notemos ainda que, logo após o panegírico do rei $\mathrm{D}$. Manuel, logo após a exaltação dos seus feitos sem paralelo, Pacheco acrescenta: Mas leixo tudo isto pera quem vossa governança houver de fazer; o que toca a cosmografia e marinharia por extenso espero dizer. $E$ ao enunciar detalhadamente o conteúdo do seu livro, de cosmografia e marinharia, Pacheco não esquece, afinal, o seu objectivo fundamental, a segurança da navegação: e isto porque esta obra leve ordem e fundamento, e a costa mais seguramente se possa navegar. Como também ao falar "da gente da Etiópia", não esquece o comércio: e assim direi do comércio que nesta terra pode haver...

Façamos finalmente entrar em jogo aquilo que foi o objectivo fundamental dêste nosso trabalho.

Um certo alarde de erudição é mais um fator a aproximar Duarte Pacheco Pereira de Gomes Eanes de Zurara, e o Esmeralldo de situ orbis da Crônica dos feitos de Guiné (212). Duarte Pacheco cita Estrabão, Ptolomeu, Alfragano, Homero, Vincent de Beauvais, Jacob Perez de Valência, Virgílio, cita a Bíblia, cita Sacrobosco e o Tratado da Esfera, cita Plínio e a História Natural, cita Pompônio Mela e o De Situ Orbis. Mas o estudo das fontes de Duarte Pacheco no Esmeraldo leva-nos a concluir que raros são os autores que êle teria lido diretamente. Cita Homero e Alfragano seguramente de segunda mão, e ou-

(212). - Ver, Joaquim de Carvalho: Sôbre a erudição de Gomes Eanes de Zurara (Notas em tôrno đe alguns plágios dêste cronista), in Estudos sôbre a Cultura Portuguêsa do Século XV, Coimbra, 1949. Ver ainda. os nossos trabalhos: Joaquim de Carvalho - Estudos sôbre a Cultura Portuguêsa do Scéculo XV (Volume I - Coimbra, 1949), in Bulletin d'Etudes Historiques, n. $\circ$, Lisboa, 1953 ; A mentalidade, o tempo e os grupos sociais (Um exemplo português da época dos descobrimentos: Gomes Eanes de Zurara e Valentim Fernandes), in Revista de História, São Paulo, n.o 15, julho-setembro de 1953; Mentalité, Temps, Groupes Sociaux (Un exemple portugais), in Annales, E.S.C., Paris, n o 4, Octobre-Décembre 1953. 
tro tanto acontece muito provàvelmente com os restantes, se exceptuarmos a Bíblia, o Tratado da Esfera de Sacrobosco, alguns livros da História Natural de Plínio, e o seu grande livro-base no que diz respeito à geografia geral: o De Situ Orbis de Pompônio Mela. Quase diríamos - numa linguagem um tanto anacrônica -, que Duarte Pacheco Pereira sofria do complexo de inferioridade de não ser um verdadeiro humanista, procurando então aparentar o que não era. Fingiria assim, leituras que não fêz, e mesmo leituras por onde as não fêz: lê o Tratado da Esfera de Sacrobosco em texto português, a História Natural de Plínio em texto italiano, o De Situ Orbis de Pompônio Mela em texto castelhano.

Ora, parece-nos que êste fato, o fato de Duarte Pacheco Pereira ter lido as suas principais fontes - talvez com exepção da Bíblia -, em línguas vulgares, define, ainda com maior nitidez o seu lugar na História da Cultura. O fato de ter lido Sacrobosco em português, Plínio em italiano, Pompônio Mela em castelhano, acrescido ainda de, muitas, ou mesmo quase tôdas, as suas citações eruditas serem de segunda mão, leva-nos a concluir que Duarte Pacheco Pereira não era apenas um fraco latinista, mas muito mais um homem de ação e um homem de ciência do que um humanista. Tinha as fraquezas e as virtudes dos homens práticos da época, que, parece-nos, deram uma contribuição muito mais poderosa para aquilo a que chamámos a pré-história do pensamento e la ciência modernas do que as Universidades, o seu corpo docente, e mesmo os humanistas, cheios de erudição.

Razão tinha Lucien Febvre, quando escreveu:

“...humanisme et science se sont développés, séparément, et sans action réciproque directe. D'une part, l'humanisme, nourri de textes et d'auteurs, exclusivement nourri de textes et d'auteurs $\ldots \ldots \ldots \ldots \ldots \ldots \ldots \ldots$.

D'autre part, les réalités. Les découvertes. Les inventions. Les techniques ....................... entre le savoir livresque et le savoir pratique, peu ou presque pas de contacts" (213).

Outro tanto diremos para as palavras, bem mais recentes, de Guy Beaujouan:

“...l'attitude érudite des humanistes n'était pas a priori plus féconde que les préoccupations théologiques (213). - Le problème de l'incroyance au XVIe siècle (La religion de Rabelais),
Edition revue, Paris, 1962, p. 414. 
des maîtres médiévaux; les plus grands savants du XV siècle furent souvent des hommes sans lettres..." (214).

Em pleno século XVI, lembremos Ambroise Paré (15101599), um autodidata, ignorante do latim, e sofrendo as injúrias e os sarcasmos da Universidade do tempo (215). Lembremos Leonardo da Vinci (1452-1519), êste contemporâneo de Duarte Pacheco (c. 1460-1533) (216), o homem que afirmou ser a experiência a mestra das coisas, precisamente no mesmo ano, 1508, em que Duarte Pacheco Pereira afirmava ser a experiência a madre idas cousas. Leonardo da Vinci, foi, pela mesma época, também, um fraco latinista, um homem de poucas letras e muito contacto com a vida. No dizer de George Sarton (217), um autodidata, um Uomo senza lettere.

Uma nova cultura surgia que não era mais tradicional, mesmo quando era oficial. O comércio, as navegações, os prenúncios da ciência e do pensamento modernos, avançam paralelamente, impondo gêneros de vida, profissões, um clima econômico, social, e cultural, ao qual, em Portugal, a própria nobreza, a própria realeza, não podia escapar - o clima da burguesia nascente e ascendente.

Duarte Pacheco Pereira foi um nobre e um servidor da realeza, mas foi também, e ao mesmo tempo, um homem cujo gênero de vida, a profissão de navegador e de técnico da navegação, o ligaram a actividades que foram como que a mola propulsora da burguesia nascente, a nova classe ascendente. Duarte Pacheco Pereira ligado à nobreza, mesmo à realeza, foi ao mesmo tempo, pela sua profissão e atividades, um militante, um intelectual, da burguesia comercial do tempo. Personagem de contradição, como só as há nas contradições de um mundo que acaba e de um outro que começa.

(214). - La Science dans l'Occident Médiéval Chrétien, in Histoire Générale des Sciences publiée sous la direction de René Taton, Tome I: La Science Antique et Médiévale (des origines à 1450), Paris. P.U.F., 1957, p. 516.

(215). - Maurice Caullery: Les Grandes Etapes des Sciences Biologiques, in Histoire de la science publiée sous la direction de Maurice Daumas, Encyclopédie de la Pléiade, Paris, 1957, p. 1171.

(216). - Ver, para as datas de nascimento e morte de Duarte Pacheco, a nossa obra já citada: L*Esmeraldo de situ orbis" de Duarte Pacheco Pereira et la littérature portugaise de voyages à l'époque des grandes découvertes, em preparação.

(217). - Léonard de Vinci, ingénieur et savant, in Léonard de Vinci et l'expérience scientifique au XVIe siècle, Colloques Internationaux du Centre National de la Recherche Scientifique, Paris, 4-7 juillet 1952, publ. du C.N.R.S. et P.U.F., 1953, ps. 18, 20. 


\title{
$-332-$ \\ BIBLIOGRAFIA
}

\author{
MANUSCRITOS.
}

Biblioteca Pública e Arquivo Distrital de Evora:

- Duarte Pacheco Pereira: Esmeraldo de situ orbis, manuscrito CXV, 1-3.

Biblioteca Nacional (Lisboa):

- Duarte Pacheco Pereira: Esmeraldo de situ orbis, manuscrito da Secção de Reservados. Fundo Geral 888 (Cota antiga: manuscrito B-17, 7).

- Sacrobosco: Tratado da Esfera, manuscrito latino da Secção de Reservados, CCCXXXIII-385, fls. 21-26.

Biblioteca da Ajuda (Lisboa):

- Pompônio Mela: De Situ Orbis, traduzido do latim para castelhano por Mestre João Faras, manuscrito 50-V-19.

Biblioteca da Academia das Ciências (Lisboa):

- Duarte Pacheco Pereira: Esmeraldo de situ orbis, cópia do manuscrito da Biblioteca Nacional (Lisboa), feita em 1879 por Silvestre Severiano Lapa.

Arquivo Nacional da Tôrre do Tombo (Lisboa):

- Bula de Nicolau $V$ de 8 de janeiro de 1455 - Bulas, maço 7, n.o 29; maço 32 , n. ${ }^{\circ} 10$; maço 33 , n. ${ }^{\circ} 14$.

- Bula de Calixto III de 13 de março de 1456 - Bulas, maço 5 , n. 7 , sétima gaveta, maço 13 , n. ${ }^{\circ} 7$; Livro dos "Mestrados", fls. 159-163.

- Bula de Sixto IV de 21 de junho de 1481 - Bulas, maço 9, n. 1 ; maço 12 , n.o 27 ; maço 19 , n. ${ }^{\circ} 37$; maço 26 , n. ${ }^{\circ} 10$; maço $35, n .^{\circ} 24$ e 34 .

- Carta de Mestre João, escrita de Vera Cruz no dia 1 de maio de 1500, Corpo Cronológico, parte 3a., maço 2, n.o 2.

- Carta de 22 de outubro de $1513 \mathrm{em}$ que é referida uma tença anual de doze mil reais a um Mestre João alemão, Chancelaria de D. Manuel, Doações, L.o 15, fl. 172.

- Documento em que é referido um "mestre joham allemã que aqui estaa", Fragmentos, maço 17.

- Carta de Duarte Pacheco Pereira ao rei D. Manuel, Cartas dos Vice-Reis, maço único, n. ${ }^{\circ} 148$.

- Carta de D. Manuel, de 20 de maio de 1514, em que êste confirma um alvará de Duarte Pacheco Pereira armando cavaleiro Fernão Velho, e em que se fala da participação de Duarte Pacheco Pereira na frota enviada em socôrro de Tânger quando esta cidade estava a ser atacada pelos exércitos do rei de Fez, Chancelaria de D. Manuel, L. 11, fl. $30 \mathrm{v}$.

- Documento assinado por Duarte Pacheco Pereira, em São Jorge da Mina, em 20 de novembro de 1519, com uma ordem a João de Figueiredo, feitor do rei, Corpo Cronológico, 2a. Parte, maço 85 , n. 200. 
- Documento assinado por Duarte Pacheco Pereira, em São Jorge da Mina, em 1 de dezembro de 1519 , em que se fala de uma entrega feita por João de Figueiredo, feitor do rei, Corpo Cronológico, 2.a Parte, maço 86 , n. ${ }^{\circ} 30$.

- Documento assinado por Duarte Pacheco Pereira, em São Jorge da Mina, em 10 de dezembro de 1519, com uma ordem a João de Figueiredo, feitor do rei, Corpo Cronológico, 2a. Parte, maço 86, n.o 80 .

- Documento assinado por Duarte Pacheco Pereira, em São Jorge da Mina, em 13 de dezembro de 1519, Corpo Cronológico, 2a. Parte, maço 86, n. ${ }^{\circ} 88$.

- Documento de $D$. Manuel, de 13 de fevereiro de 1520, dispensando um cavaleiro residente em São Jorge da Mina do pagamento de uma dívida à feitoria, Corpo Cronológico, 1a. Parte, maço 25, doc. 123.

- Documento assinado por Duarte Pacheco Pereira em São Jorge da Mina, em 8 de agosto de 1520, com ordens a João de Figueiredo, feitor do rei, Corpo Cronológico, 2a. Parte, maço 91, doc. 28.

- Documento assinado por Duarte Pacheco Pereira em São Jorge da Mina, em 8 de agosto de 1520, com ordens a João de Figueiredo, feitor do rei, Corpo Cronológico, 2a. Parte, maço 91 , doc. 27.

- Documento de nomeação, em 4 de julho de 1522, por D. João III, do governador que substituiu Duarte Pacheco Pereira em São Jorge da Mina, Chancelaria de D. João III, L. 51, fl. $184 \mathrm{v}$.

- Miguel Cerqueira Doce: Vitórias de Duarte Pacheco, e de outros capitaens, que com valor, e esforço militarão na India Oriental, poema em dez cantos, rimas oitavas, manuscrito redigido em 1631. Manuscrito desaparecido. Temos dêle notícia através de Diogo Barbosa Machado (Biblioteca Lusitana, Lisboa, 1752, Tomo III, p. 464) e de Sousa Viterbo (Trabalhos náuticos dos portuguêses nos séculos XV e XVII, Lisboa, 1898, 1a. Parte, ps. 339-340). Barbosa Machado diz ter êste manuscrito pertencido à Biblioteca do Márquês de Abrantes.

\section{$* * *$ \\ INCUNABULOS.}

Biblioteca Nacional (Paris):

- Bíblia Latina, Venetiis, Hịeronymus de Paganinis, 1492 (Cota: Rés. A. 5640).

- Bíblia Latina, Venetiis, Simon Bevilaqua, 1494 (Rés. A. 2343 et 2344). 
- Bíblia Latina, Venetiis, Hieronymus de Paganinis, 1497 (Rés. A. 5645).

- Bíblia Latina, Venetiis, Simon Bevilaqua, 1498 (Rés. A. 2347 et 2348 ).

- Jacob Perez de Valência: Commentaria in Psalmos, Valência, 1484 (Rés. A. 1011).

- Plínio, o Antigo: Historia naturalis Caii Plinii, ex recensione Joannis Andreae, Venetiis, 1472 (Rés. S. 413).

- Plínio, o Antigo: Caii Plinii Secundi Historia naturalis ex emendatione Philippi Beroaldi, Parmae, 1476 (Rés. S. 108).

- Plínio, o Antigo: Historia Naturale di C. Plinio Secondo, tradocta di lingua latina in fiorentina per Christophoro Landino Fiorentino al Serenissimo Ferdinando Re di Napoli, Venetiis, 1476 (Rés. S. 132).

- Plínio, o Antigo: Naturale historia di G. Plinio Secondo, tradocta in lingua fiorentina per Christophoro Landino, Venetiis, 1481 (Rés. S. 133).

- Pompônio Mela: Pomponii Melae Cosmographiae liber, Mediolani, 1471 (Rés. G. 1233).

- Pompônio Mela: Pomponii Melae Cosmographiae liber, Venetiis, 1477 (Rés. G. 2015).

- Pompônio Mela: Pomponii Melle cosmographi de Situ orbis liber primum-tertius, Venetiis, 1478 (Rés. G. 1018).

- Pompônio Mela: Pomponii Mellae Cosmographi Geographia, Prisciani quoque rex Dyonisio Thessalonicensi de Situ Orbis interpretatio, Venetiis, 1482 (Rés. G. 1234).

- Pompônio Mela: Hermolai Barbari castigationes Plinianae. Item emendatio in Melam Pomponium, Romae, 1492-1493 (Rés. S. 334 et 335).

- Pompônio Mela: Pomponius Mela, Cosmographia, sive de Situ orbis, Romae, 1493 (Rés. G. 1017 et 1236).

- Ptolomeu: Claudii Ptolemaei Geographia, Romae, 1490 (Rés. G. 39,466 et 467 ).

- Sacrobosco: Joannis de Sacro Bosco Sphaera mundi, vel Tractatus de Sphaera Gerardi Cremonensis. Theorica planetarum. Venetiis, per F. Renner de Hailbrun, 1478 (Rés. V. 1012 et 1025 et $\mathrm{p}$. V. 156).

- Sacrobosco: Joannis de Sacro Bosco Sphaera mundi. Joannis de Monteregio Disputationes contra Cremonensia in planetarum theoricas deliramenta. Georgii Purbachii in motus planetarum theoricae. Venetiis, E. Ratdolt, 1482 (Rés. V. 1013 et p. V. 160).

-- Sacrobosco: Ibidem, 1485 (Rés. V. 1014, 1015, p. V. 161, 349 et 362).

- Sacrobosco: Ibidem, 1488 (J. Santritter et H. de Sanctis) (Rés. p. V. 390).

- Sacrobosco: Ibidem, 1490 (Rés. V. 1016).

- Sacrobosco: Joannis de Sacro Bosco Sphaera mundi, una cum additionibus insertis ac familiarissima textus expositione $\mathbf{P e}^{-}$ 
tri de Alliaco, Parisis, per W. Hopyl, 1494 (Rés. m. P. 55 et 58 ).

- Sacrobosco: Uberrimum Joannis de Sacro Bosco Sphaere mundi commentum Petri Cirnelli, insertis etiam questionibus Petri de Aliaco, Parisiis, J. Petit, impensis G. Mercatoris, 1498 (Rés: V. 203 et 611).

- Sacrobosco: Joannis de Sacro Bosco Sphaera mundi, cum tribus commentis nuper editis, videlicet Cicehi Esculani, Francisci Capuani de Manfredonia et Jacobi Fabri Stapulensis. Theoricae novae planetarum Georgii Purbachii et in eas Francisci Capuani de Manfredonia expositio. Venetiis, per S. Papiensem, 1499 (Rés. V. 199-200).

- Sacrobosco: Textus de Sphera Johannis de Sacro Bosco, cum additione..., Parisiis, per W. Hopyl, 1500 (Rés. m. V. 42 et 43 ).

- Estrabão: de Situ orbis (Venetiis), per Joannem (Rubeum) Vercellensem, 1494 (Rés. G. 19 et 514).

- Vincent de Beauvais: Speculum Historiale, 4 Volumes, 1473 (Rés. G. 192-195).

- Vincent de Beauvais: Speculum Historiale, 3 Volumes, 1474 (Rés. G. 196-198).

- Vincent de Beauvais: Speculum Historiale, s/d (só o Speculum Morale é datado de 1476) (Rés. G. 185-191; G. 188-191).

- Vincent de Beauvais: Speculum Historiale, Nuremberg, 5 Volumes, 1483-1486 (o Quadruplex: Speculum Naturale, Speculum Doctrinale, Speculum Morale, Speculum Historiale) (Rés. G. 531-540).

- Vincent de Beauvais: Speculum Historiale, 1494 (Rés. G. 201).

- Vincent de Beauvais: Le miroir historial, 5 Volumes, Paris, 1495 (Rés. G.. 203-207).

- Virgílio: Opera cum Servii commentariis, Venetiis, 1487 (Rés. m. Yc. 1042).

- Virgílio: Publii Virgilii Maronis opus, a Paulo Andelocensi exactissime emendatum, Parisiusque in vico Sorbonico quam tersissime impressum, finitur, Anno 1489 (Rés. M. Yc. 1044).

- Virgílio: Georgica cum commento, Paris, 1492 (Rés. p. Yc. 1572).

- Virgílio: Liber Georgicorum Virgilli, cum commento familiari, Lyon, 1493 (Rés. p. Yc. 1670-2).

Biblioteca Nacional (Madrid):

- Pompônio Mela: De Situ Orbis, Valencia, por Lamberto Palmart, 1482.

Biblioteca Nacional (Rio de Janeiro):

- Pompônio Mela: Cosmographia, ed. Nuñes de la Yerva. Salamanca, 1498 (n. ${ }^{\circ} 122$ do Catálogo de Incunábulos da Biblioteca Nacional do Rio de Janeiro, Ministério da Educação e Cultura, 1956). 


\section{LIVROS E ARTIGOS.}

- Academia das Ciências de Lisboa: Bibliografia Geral Portuguêsa do Século XV, Volume II, Lisboa, 1942 .

- Academia Portuguêsa da História: "Esmeraldo de situ orbis" por Duarte Pacheco Pereira, 3a. ed., Introdução e Anotataçốes Históricas pelo Acadêmico de Número Damião Peres, Lisboa, MCMLIV.

- Albuquerque (Luís Mendonça de): As navegações e as origens da mentalidade científica, in História da Cultura em Portugal de Antônio José Saraiva, Volume II, Lisboa, 1953.

- Albuquerque (Luís Mendonça de): Sôbre um manuscrito quatrocentista do "Tratado da Esfera" de Sacroboseo, in Revista da Faculdade de Ciências da Universidade de Coimbra, Volume XXVIII, Coimbra, 1959.

- Albuquerque (Luís Mendonça de): o primeiro guia náutico portnguês o problema das latitudes na marinha dos séculos XV e XVI, in Revista da Universidade de Coimbra, Volume XIX, 1960.

- Alguns documentos do Arquivo Nacional da Tôrre do Tombo àcêrca das navegações e conquistas portuguêsas, publicados por ordem do Governo de S. Magestade Fidelíssima ao celebrar-se a comemoração quadricentenária do descobrimento da América, com um Prólogo de José Ramos Coelho, Lisboa, 1892 .

- Anais da Academia Portuguêsa da História, 2a. série, Volume I, Lisboa, 1946.

- Anselmo (Antônio Joaquim): Bibliografia das obras impressas em Portugal no século XVI, Lisboa, 1926.

- Aulete (F. J. Caldas): Dicionário Contemporâneo da Língua Portuguêsa..., 2a. ed., 2 Volumes, Lisboa, 1925.

- Barros (João de): Ásia, Primeira Década, 4a. ed. revista e prefaciada por Antônio Baião, Coimbra, 1932.

- Barros (João de): Ásia, 6a. ed., por Hernâni Cidade, 4 Volumes, Lisboa, 1945-1946.

- Basto (Martins): Breve resumo dos privilégios da nobreza..., Lisboa, 1854.

- Basto (Raphael Eduardo de Azevedo): "Esmeraldo de situ orbis" por Duarte Pacheco Pereira, edição comemorativa da descoberta da América por Christovão Colombo no seu quarto centenário sob a direcção de..., Lisboa, 1892.

- Beaujouan (Guy) : La Science dans l'Occident Médiéval Chrétien, in Histoire Générale des Sciences publiée sous la direction de René Taton, Tome I: La Science Antique et Médiévale (des origines à 1450), Paris, P.U.F., 1957.

- Beaujouan (Guy): Science Livresque et Art Nautique au XVe Siècle, in Les aspects internationaux de la découverte océanique aux XVe. et XVIe. siècles, Actes du cinquième Colloque International d'Histoire Maritime, Bibliothèque Gé- 
nérale de l'École Pratique des Hautes Études, VIe Section, S.E.V.P.E.N., Paris, 1966.

- Bellido (Antônio Garcia y): España y los españoles hace dos mil años según la geografia de Strabon, 2a. ed., Colecção Austral, Buenos Aires-Mexico, 1945.

- Bensaude (Joaquim): L'astronomie nautique au Portugal à l'époque des grandes découvertes, Berne, 1912.

- Bensaude (Joaquim): Tractado da Spera do Mundo, Regimento da declinação do sol, Reproduction fac-similé du seul exemplaire connu appartenant à la Bibliothèque d'Evora, Genève, s/d.

- Bensaude (Joaquim): Regimento do Estrolábio e do Quadrante, Tractado da Spera do Mundo, Reproduction fac-similé du seul exemplaire connu appartenant à la Bibliothèque Royale de Munich, Munique, 1914.

- Bensaude (Joaquim): Les légendes allemandes sur l'histoire des découvertes maritimes portugaises, Genève, 1917-1922.

- Biblia Sacra Vulgatae editionis, Lyon, 1682.

- Biblia Sagrada contendo o Velho e o Novo Testamento, traduzida em português segundo a Vulgata Latina pelo Padre Antonio Pereira de Figueiredo. Edição aprovada em 1842 pela Rainha D. Maria II com a consulta do Patriarcha Arcebispo eleito de Lisboa, Lisboa, 1918.

- Biblia Medieval Portuguêsa, edição de Serafim da Silva Neto, Rio de Janeiro, s/d.

- Bourdon (Léon), avec la collaboration de Ricard (Robert), Rafols (E. Serra), Monod (Th.), Mauny (R.), Beaujouan (Guy): Gomes Eanes de Zurara: Chronique de Guinée, Dakar, 1960.

- Bourgey (Louis):Observation et Expérience chez Aristote, Paris, 1955.

- Bullarium patronatus Portugalliae regum in ecclesiis Africae, Asiae atque Oceaniae, bullas, brevia, epistolas, decreta actaque Sanctae Sedis ab Alexandro. III ad hoc usque tempus amplectens, curante Levy Maria Jordão..., Olisipone, 18681879.

- Caminha (Pedro de Andrade): Poesias, publicadas pela Academia Real das Ciências de Lisboa, 1791.

- Camões (Luís de): Lusíadas, ed. da Imprensa Nacional, texto estabelecido por José Maria Rodrigues, Lisbóa, 1931.

- Cartier (Jacques): Brief récit, et succinte narration de la navigation faicte es Ysles du Canada, Hochelage et Saguenay et autres, avec particulieres moeurs, langaiges, et cerimonies des habitans d'icelles: fort delectable a veoir, 1545 (Réimpréssion: Paris, Tross, 1863; reproduction photomécanique: $\mathrm{Pa}-$ ris, 1937).

- Carvalho (Joaquim Barradas de): As idéias políticas e sociais de Alexandre Herculano. Lisboa, 1949.

- Carvalho (Joaquim Barradas de): Joaquim de Carvalho-Estudos sôbre a Cultura Portuguêsa do Século XV (Volume I - 
Coimbra, 1949), in Bulletin d'Etudes Historiques, n. ${ }^{\circ}$, Lisboa, 1953.

- Carvalho (Joaquim Barradas de): A mentalidade, o tempo e os grupos sociais (Um exemplo português da época dos descobrimentos: Gomes Eanes de Zurara e Valentim Fernandes), in Revista de História, São Paulo, n. ${ }^{\circ} 15$, julho-setembro de 1953.

- Carvalho (Joaquim Barradas de): Mentalité, Temps, Groupes Sociaux (Un exemple portugais), in Annales, E.S.C., n.o 4, Paris, octobre-décembre 1953.

- Carvalho (Joaquim Barradas de): Sur l'introduction et la diffusion des chiffres arabes au Portugal, in Bulletin des fudes Portugaises et de l'Institut Français au Portugal, Tome XX, 1958.

- Carvalho (Joaquim Barradas de): L'historiographie portugaise contemporaine et la littérature de voyages à l'époque des grandes découvertes, in Ibérida - Revista de Filologia —, n. ${ }^{\circ}$, Rio de Janeiro, dezembro de 1960 .

- Carvalho (Joaquim Barradas de): Um inédito de Duarte Pacheco Pereira existente na Biblioteca da Ajuda, in Diário de Lisboa, 17 e 19 de julho de 1961.

- Carvalho (Joaquim Barradas de): Um inédito de Duarte Pacheco Pereira, in Boletim Internacional de Bibliografia Luso-Brasileira, Fundação Calouste Gulbenkian, Lisboa, n. 4, Volume II, outubro-dezembro de 1961.

- Carvalho (Joaquim Barradas de): Algarismo, in Dicionário de História de Portugal dirigido por Joel Serrão, Iniciativas Editoriais, Lisboa, 1962.

- Carvalho (Joaquim Barradas de): "Esmeraldo de situ orbis" de Duarte Pacheco Pereira (Edition critique et commentée), in Positions des Thèses de Troisième Cycle soutenues devant la Faculté en 1960 et 1961, Publications de la Faculté des Lettres et Sciences Humaines de Paris, P.U.F., Paris, 1962.

- Carvalho (Joaquim Barradas de): As fontes de Duarte Pacheco Pereira no "Esmeraldo de situ orbis" (Breve apontamento), in Publicaciones del Curso Hispano-Portugues de Orense, 1963.

- Carvalho (Joaquim Barradas de): A decifracão de um enigma: o título "Esmeraldo de situ orbis", in Diário de Lisboa, 23 de maio de 1963.

- Carvalho (Joaquim Barradas de): Ibidem, in Boletim Internacional de Bibliografia Luso-Brasileira, Fundação Calouste Gulbenkian, Volume IV, n.o 4, outubro-dezembro de 1963.

- Carvalho (Joaquim Barradas de): Ibidem, in Revista de História, São Paulo, n.o 58, abril-junho de 1964.

- Carvalho (Joaquim Barradas de): As Edições e as Traduções do "Esmeraldo de situ orbis", in Revista de História, São Paulo, n. 59 , julho-setembro de 1964 .

- Carvalho (Joaquim Barradas de): O "Esmeraldo de situ orbis" de Duarte Pacheco Pereira na História da Cultura, in Re- 
vista de História, n.o 60, São Paulo, outubro-dezembro de 1964.

- Carvalho (Joaquim Barradas de): Esmeraldo de situ orbis, in Dicionário de História de Portugal dirigido por Joel Serrão, Iniciativas Editoriais, Lisboa, 1965.

- Carvalho (Joaqum Barradas de): Mestre João ou Mestre João Faras, in Dicionário de História de Portugal dirigido por Joel Serrão, Iniciativas Editoriais, Lisboa, 1965.

- Carvalho (Joaquim Barradas de): A Literatura Portuguêsa de Viagens da Época dos Descobrimentos, in o descobrimento do Brasil através dos textos (Edições críticas e comentadas). I. - A "Carta" de Pero Vaz de Caminha, in Revista de História, n. ${ }^{\circ}$ 65, São Paulo, janeiro-março de 1966.

- Carvalho (Joaquim Barradas de): Duarte Pacheco Pereira, in Dicionário de História de Portugal dirigido por Joel Serrão, Iniciativas Editoriais, Lisboa, 1966.

- Carvalho (Joaquim Barradas de): Literatura de Viagens, in Dicionário de História de Portugal dirigido por Joel Serrão, Iniciativas Editoriais, Lisboa, no prelo.

- Carvalho (Joaquim Barradas de): "Esmeraldo de situ orbis" de Duarte Pacheco Pereira (Édition critique et commentée), no prelo.

- Carvalho (Joaquim Barradas de): La traduction espagnole du "De Situ Orbis" de Pomponius Mela par Me. Joan Faras et les notes marginales de Duarte Pacheco Pereira, em preparação.

- Carvalho (Joaquim Barradas de): L'“Esmeraldo de situ orbis" de Duarte Pacheco Pereira et la littérature portugaise de voyages à l'époque des grandes découvertes (Contribution à l'étude des origines de la pensée moderne), em preparação.

- Carvalho (Margarida Barradas de): L'idéologie religieuse dans la "Carta" de Pero Vaz de Caminha, in Bulletin des ftudes Portugaises et de l'Institut Français au Portugal, Tome XXII, 1960.

- Carvalho (Margarida Barradas de): Natureza e Naturalismo no "Esmeraldo de situ orbis" de Duarte Pacheco Pereira, em preparação.

- Carvalho (Joaquim de): Sôbre a erudição de Gomes Eanes de. Zurara (Notas em tôrno de alguns plágios dêste cronista), in Estudos sôbre a Cultura Portuguêsa do Sécuḷo XV, Coimbra, 1949.

- Castanheda (Fernão Lopes de): História do Descobrimento e Conquista da India pelos Portuguêses, 3a. ed. por Pedro de Azevedo, Coimbra, 1924.

- Catálogo de Incunábulos da Biblioteca Nacional do Rio de Janeiro, Ministério de Educação e Cultura, 1956 (Nota Preliminar de Celso Ferreira da Cunha; Introdução de Rosemarie Erika Horsh). 
- Caullery (Maurice): Les Grandes Etapes des Sciences Biologiques, in Histoire de la Seience publiée sous la direction de Maurice Daumas, Encyclopédie de la Pléiade, Paris, 1957.

- Cordeiro (Jacinto): Prospera e adversa fortuna de Duarte Pacheco Pereira, em duas comédias pelo Alferes Jacinto Cordeiro, publicadas em Portugal por Craesbeck em 1630.

- Correia (Gaspar): Lendas da f́ndia, publicadas sob a direcção de Rodrigo José de Lima Felner, Lisboa, 1858.

- Cortesão (Armando): Cartografia e Cartógrafos Portuguêses dos Séculos XV e XVI (Contribuição para um estudo completo), Volume I, Lisboa, 1935.

- Cortesão (Armando) e Mota (Avelino Teixeira da): Portugaliae Monumenta Cartographica, Volume I, Lisboa, 1960.

- Costa (A. Fontoura da): A Marinharia dos Descobrimentos, 2a. ed. correcta e aumentada, Lisboa, 1939.

- Costa (A. Fontoura da): La lieu marine des Portugais aux XVe-XVIe siècles, in Boletim da Sociedade de Geografia de Lisboa, 56a. 'série, n. ${ }^{\circ}$ 9-10, setembro-outubro de 1938.

- Costa (A. Fontoura da): Os sete únicos documentos de 1500 conservados em Lisboa referentes à viagem de Pedro Álvares Cabral, Lisboa, 1940.

- Dias (Augusto Epiphanio da Silva): "Esmeraldo de situ orbis" por Duarte Pacheco Pereira, in Boletim da Sociedade de Geografia de Lisboa, 1903-1904. A mesma edição em volume, em 1905.

- Dias (Carlos Malheiro): A Semana de Vera Cruz, in História da Colonização Portuguêsa do Brasil, Volume II, Pôrto, 1923.

- Estrabão: de Situ orbis - In-fol. Impressum Venetiis, per Bertholomeum de Zanis de Portesio, ano Domini M.CCCCC. II, die XIII, januari. Venetiis, 1502.

- Febvre (Lucien): Le problème de l'incroyance au XVIe siècle (La Religion de Rabelais), Paris, 1947. Édition revue, Paris, 1962.

- Godinho (Vitorino Magalhães): Documentos sôbre a Expansão Portuguêsa, Volume I, Lisboa, 1943.

- Godinho (Vitorino Magalhães): Duarte Leite e a evolução dos estudos em história dos descobrimentos, in Duarte Leite: História dos Descobrimentos (Colectânea de esparsos, organização, notas e estudo final de Vitorino Magalhães Godinho), Volume II, Lisboa, 1962.

- Gois (Damião de): Crônica del-rei D. Manuel, Biblioteca de Clássicos Portuguêses, 12 Volumes, Lisboa, 1909-1912.

- Haebler (Conrado): Bihliografia Ibérica del Siglo XV, Leipzig, La Haya, 1904 e 1917.

- Historisches Jahrbuch, Munchen, 1908.

- Homère: Odyssée, édition "Les Belles Lettres", Paris.

- I manoscritti e i designi di Leonardo da Vinci publicati dalla Reale Commissione Vinciana..., serie minore, 5 Vol., Roma, 
1930-1936 (Codex Forster-South Kensington Museum, London).

- Indice das Bulas existentes no Arquivo Nacional da Tôrre do Tombo, em Lisboa.

- Kimble (George H. T.): "Esmeraldo de situ orbis" by Duarte Pacheco Pereira, translated and edited by..., Hakluyt Society, London, 1937.

- Koyré (Alexandre): Etudes Galiléennes - I - A l'aube de la Science Classique, Paris, 1939.

- Koyré (Alexandre): L'apport scientifique de la Renaissance, in Revue de Synthèse, janvier-juin 1950 .

- Leite (Duarte): História dos Descobrimentos (Colectânea de esparsos, organização, notas e estudo final de Vitorino Magalhães Godinho), Volume I, Lisboa, 1959.

- Lenoble (Robert): Mersenne ou la naissance du mécanisme, Paris, 1943.

- Lenoble (Robert): Origines de la pensée scientifique moderne, in Histoire de la Science, publiée sous la direction de Maurice Daumas, Encyclopédie Pléiade, Paris, 1957.

- Machado (Diogo Barbosa): Biblioteca Lusitana, Tomo I, Lisboa, 1741. (2a. ed., Lisboa, 1930).

- Marco Paulo - o Livro de Nicolao veneto - Carta de Jerônimo de Santo Estevam, conforme a impressão de Valentim Fernandes,feita em Lisboa, em 1502; com três fac-similes, introdução e índices por Francisco Maria Esteves Pereira, Lisboa, 1922.

- Matos (Luís de): L’Expansion Portugaise dans la Littérature Latine de la Renaissance (Thèse Sorbonne), exemplares dactilografados, Paris, s/d.

- Mauny (Raymond): "Esmeraldo de situ orbis" (Côte Occidentale d'Afrique du Sud Marocain au Gabon) par Duarte Pacheco Pereira (vers 1506-1508), Centro de Estudos da Guiné Portuguêsa, Bissau, 1956.

- Mela (Pompônio): Compendio geographico i historico de el orbe antiguo, i descripción de el sitio de la tierra escripta por Pomponio Mela, Español antiguamente en la republica romana... restituido a la suia española de la libreria de Don Jusepe Antonio Gonzales de Salas, Madrid, 1644.

- Mela (Pompônio): De Situ Orbis, traduit en français sur l'édition D'Abraham Gronovius... par C. P. Fradin, ParisPoitiers, 3 Tomes, 1804.

- Mela (Pompônio): Géographie de Pomponius Mela, traduite par M. Louis Baudet, C. L. F. Panckoucke Editeurs, Paris, 1843.

- Mela (Pompônio): Macrobe (Oeuvres Complètes), Varron (De la langue latine), Pomponius Mela (Oeuvres Complètes), avec la traduction en français, publiée sous la direction de $M$. Nisard, Paris, 1845.

- Mela (Pompônio): Pomponii Melae de Chorographia libri tres recognovit Carolus Frick, Lipsiae, 1880. 
- Mieli (AIdo): Lionardo da Vinci, Panorama General de Historia de la Ciencia, IV, Madrid-Buenos Aires, 1950.

- Miranda (Francisco Sá de): Obras Completas, Texto estabelecido, Notas e Prefácio por M. Rodrigues Lapa, 2 Volumes, Lisboa, 1937.

- Moldenhauer (Gerhard): Contribución al catalogo de manuscritos españoles existentes en bibliotecas portuguesas, in $\mathbf{R e}-$ vista de Archivos, Bibliotecas y Museus..., Tomo XLIX, Madrid, 1928.

- Monod (Th.), Mota (A. Teixeira da), Mauny (R.): Deseription de la Côte Occidentale d'Afrique (Sénégal au Cap de Monte, Archipels) par Valentim Fernandes (1506-1510), Bissau, 1951.

- Mota (A. Teixeira da): A evolução da ciência náutica durante os séculos XV-XVI na cartografia portuguêsa da época, edição da Junta de Investigações do Ultramar, Lisboa, 1961.

- Mota (A. Teixeira da): Bartolomeu Dias e o valor do grau terrestre, in Actas do Congresso Internacional da História dos Descobrimentos, Volume II, Lisboa, 1961.

- O. Manuscrito Valentim Fernandes, edição da Academia Portuguêsa da História, Lisboa, 1940.

- Osório (Jerônimo): Histoire de Portugal, contenant les entreprises, navigations, \& gestes memorables des Portugallois, tant en la conqueste des Indes Orientales par eux descouvertes, qu'ès guerres d'Afrique \& autres exploits, depuis l'an mil quatre cens nonãte six, sous Emmanuel premier du nom. Paris, 1581 .

- Osório (Jerônimo): L'Histoire de Portugal, comprise en deux volumes, contenans infinies choses memorables avenues depuis l'an du Seigneur M. XC., jusques à l'an MDCX sous le regne de vingt Roys. Genève, MDCX.

- Pimentel (Manuel): A arte de navegar, Lisboa, 1762.

- Pina (Ruy de): Chronica do Senhor Rey D. Affonso $V$ escrita por ..., chronista mór de Portugal, e Guarda mór da Torre do Tombo, in Coleç̧ão de Livros Inéditos de História Portuguesa..., publicados por ordem da Academia Real das Ciências de. Lisboa por José Corrêa da Serra, Tomo I, Lisbọa, 1790

- Pina (Ruy de): Crônica de El-Rey Dom João II de Rui de Pina, edição de Alberto Martins de Carvalho, Coimbra, 1950.

- Piumati (G.): Il Codice Atlantico di Leonardo da Vinci nella Biblioteca Ambrosiana di Milano riprodotto e pubblicatto dalla Regia Accademia di Lincei..., 6 Vol., Milano, 1894-1904, Codex Atlanticus.

- Pline l'Ancien: Histoire Naturelle..., avec la traduction en français par M. E. Littré, 2 Volumes, Paris, 1848-1850.

- Pline l'Ancien: Histoire Naturelle, Livre I, Textè établi, traduit et commenté par Jean Beaujeu, Paris, éd. "Les Belles Lettres", 1950. 
- Pline l'Ancien: Histoire Naturelle, Livre II, Texte établi, traduit et commenté par Jean Beaujeu, Paris, éd. "Les Belles Lettres", 1950.

- Pline l'Ancien: Histoire Naturelle, Livre VIII, Texte établi, traduit et commenté par A. Ernout, Paris, éd. "Les Belles Lettres", 1952.

- Pline l'Ancien: Histoire Naturelle, Livre IX, Texte établi, traduit et commenté par E. de Saint-Denis, Paris, éd. "Les Belles Lettres", 1955.

- Pline l'Ancien: Histoire Naturelle, Livre XI, Texte établi, tradoit et commenté par A. Ernout et le Dr. R. Pépin, Paris, éd. "Les Belles Lettres", 1947.

- Pline l'Ancien: Histoire Naturelle, Livre XII, Texte établi, traduit et commenté par A. Ernout, Paris, éd. "Les Belles Lettres", 1949.

- Pline l'Ancien: Histoire Naturelle, Livre XIII, Texte établi, traduit et commenté par A. Ernout, Paris, éd. "Les Belles Lettres", 1956.

- Pline l'Ancien: Histoire Naturelle, Livre XIV, Texte établi, traduit et commenté par J. André, Paris, éd. "Les Belles Lettres", 1958.

- Pline l'Ancien: Histoire Naturelle, Livre XXVI, Texte établi, traduit et commenté par A. Ernout et le Dr. R. Pépin, Paris, éd. "Les Belles Lettres", 1957.

- Pline l'Ancien: Histoire Naturelle, Livre XXVII, Texte établi, traduit et commenté par A. Ernout, Paris, éd. "Les Belles Lettres", 1959.

-. Pline l'Ancien: Histoire Naturelle, Livre XXXIV, Texte établi et traduit par $H$. Le Bouniec, commenté par H. Gallet de Santerre, et par H. Le Bouniec, Paris, éd. "Les Belles Lettres", 1953.

- Privat-Deschanel, Focillon (A.): Dictionnaire des Sciences Théoriques et Appliquées, Paris, 1883.

- Ptolémée: Geographia, - Firmin-Didot, Paris, 1901.

- Révah (I. S. ): "Esmeraldo de situ orbis" de Duarte Pacheco Pereira éd. de l'Academia Portuguêsa da História, Lisboa, 1954-1955. - Compte-rendu in Bulletin des Etudes Portugaises et de l'Institut Français au Portugal, Tome XIX, 19551956.

- Ricard (Robert): La Côte Atlantique du Maroc au début du XVIe siècle d'après des instructions nautiques portugaises, dans Hespéris, Paris, 1927-2e Trimestre.

- Ricard (Robert): Les Portugais et le Sahara Atlantique au XVe siècle, in Hespéris, Tome IX, 1930.

- Rivara (Joaquim Heliodoro da Cunha): Duarte Pacheco, in Panorama, n.o 192, Volume 5, 1841.

- Rivara (Joaquim Heliodoro da Cunha): Catálogo dos manuscritos da Biblioteca Pública Eborense, Tomo I, Lisboa, 1850. 
- Sacrobosco: Sphaera mundi Johannis de Sacro Bosco..., Venetiis, per Jo. Baptista Sessa, anno salutis 1501, die vere 3 decembris.

- Sacrobosco (Iean de): La Sphère, Paris, 1576.

- Sanz (D. Manuel Serrano y): Origenes de la Dominación Española en America, Tomo Primero, Madrid, 1918, Nueva Biblioteca de Autores Españoles, T. 25.

- Sarton (George): Léonard de Vinci, ingénieur et savant, in Léonard de Vinci et l'expérience scientifique au XVIe siècle, Colloques Internationaux du Centre National de la Recherche Scientifique, Paris, 4-7 juillet 1952, publ. du C. N. R. S. et P. U. F.

- Sergio de Sousa (Antonio): Historia de Portugal, Col. Labor, Barcelona-Buenos Aires, 1929.

- Serrão (Joel) e Grácio (Rui): Breve Antologia Filosófica, Volume II, Lisboa, 1954.

- Silva (Antônio Dinys da Cruz e): Odes Pindáricas, Londres, 1820.

- Silva (Antônio de Morais e): Dicionário da lingua Portutuguêsa, 2 Volumes, Lisboa, 1823.

- Silva (Luciano Pereira da): Duarte Pacheco Pereira - precursor de Cabral, in História da Colonização Portuguêsa do Brasil, Volume I, Porto, 1921.

- Silva (Luciano Pereira da): Obras Completas, Volume II, Lisboa, 1945.

- Thorndike (Lynn): The Sphere of Sacrobosco and Its Commentators, The University of Chicago Press, 1949.

- Vasconcelos (Carolina Michaëlis de): Uma obra inédita do Condestável D. Pedro de Portugal, in Homenage à Menendez y Pelayo en el año vigesimo de su Professorado, Estudios de erudición española con um Prologo de D. Juan Valera, 2 Volumes, Madrid, 1889.

- Vasconcelos (Carolina Michaëlis de): Condestável D. Pedro de Portugal, Tragédia de la insigne Reina D. Isabel, 2a. edição, revista e prefaciada por..., Coimbra, 1922.

- Vasconcelos (Frazaão de): Um documento inédito que importa à História dos Descobrimentos, in Petrus Nonius, Volume, I, n. ${ }^{\circ}$ s 1-2, Lisboa, 1937.

- Vigouroux (F.): Dictionnaire de la Bible, publié par..., Tome Premier, Paris, 1926.

- Virgílio: Publii Virgilii Maronis Opera, Argentinae, 1502.

- Virgílio: Géorgiques, Texte établi et traduit par $\mathrm{E}$. de SaintDenis, Paris, 1956 (Édition "Les Belles Lettres").

- Viterbo (Sousa): Artes e Artistas em Portugal, Lisboa, 1892.

- Viterbo (Sousa): Trabalhos náuticos dos portuguêses nos séculos XVI e XVII, 2 Volumes, Lisboa. 1898-1900.

- Witte ( Ch. M. de): Les Bulles Pontificales et l'Expansion Portugaise at XVe siècle (Extrait de la Revue d'Histoire Ecclésiastique, t. XLVIII (1953), t. XLIX (1954), t. LI (1956), t. III (1958), Louvain, 1958. 
- Zurara (Gomes Eanes de): Crônica do descobrimento e conquista da Guiné, segundo o manuscrito da Biblioteca Nacional de Paris, modernizada, com notas, glossário, e uma introdução de José de Bragança, 2 Volumes, Porto, 1937.

- Zurara (Gomes Eanes de): Crônica dos feitos de Guiné, edição da Agência Geral das Colonias, Lisboa, 1949.

JOAQUIM BARRADAS DE CARVALHO Professor de História da Civilização Ibérica da Faculdade de Filosofia, Ciênclas e Letras da Universidade de São Paulo. 